\title{
165 rDNA sequencing of Ruminococcus albus and Ruminococcus flavefaciens: design of a signature probe and its application in adult sheep
}

\author{
Denis O. Krause, ${ }^{1}$ Brian P. Dalrymple, ${ }^{1}$ Wendy J. Smith, ${ }^{1}$ \\ Roderick I. Mackie ${ }^{2}$ and Christopher S. McSweeney'
}

Author for correspondence: Denis O. Krause. Tel: +6173214 2723. Fax: +61732142881.

e-mail: denis.krause@tag.csiro.au

1 CSIRO Division of Tropical Agriculture, Long Pocket Laboratories, Private bag \# 3, Indooroopilly 4068, Australia

2 Department of Animal Sciences, University of Illinois, Urbana, USA

\begin{abstract}
The ruminococci are an important group of fibrolytic bacteria inhabiting the rumen. Seventeen strains of presumptively identified Ruminococcus were evaluated by a combination of nearly complete and partial 165 rDNA sequence that identified all strains as either Ruminococcus albus or Ruminococcus flavefaciens. All sequences fell into cluster IV of the clostridia, while other species of ruminococci (eg. Ruminococcus obeum, Ruminococcus gnavus, Ruminococcus lactaris) fall into cluster XIVa of the clostridia. Ruminococcus cluster IV sequences were used to design a 165 rRNA oligonucleotide probe to assess the relative abundance of target populations in a stable ruminal environment. A stable population (animals fed eight times per day) was established in sheep so that statistically robust comparisons could be made in the absence of variation due to diurnal rumen fluctuations. The steady state populations were sampled six times over a $24 \mathrm{~d}$ period and direct microscopic counts (DC), total culturable counts (TCC), and total cellulolytic counts (CEL) were determined. DC and culturable data (TCC and CEL) were compared with relative abundance estimates of Ruminococcus IV and Fibrobacter succinogenes. A combination of the Ruminococcus and F. succinogenes probes accounted for $\mathbf{4 . 0} \%$ of the bacterial population and cellulolytic bacteria (measured by most-probable numbers) were $5 \cdot 2 \%$ of the total culturable count. These data suggest that a major portion of the Ruminococcus and Fibrobacter diversity has been cultured and is represented by available sequences. Steady state populations were measured over several days in three sheep and an estimate of variation in DC, TCC, CEL and 16S-based data were obtained. These variance estimates could be used to determine the theoretical sample sizes required to obtain statistically significant differences under different experimental conditions.
\end{abstract}

Keywords: Ruminococcus, $16 \mathrm{~S}$ rDNA, phylogeny, statistics, rumen

\section{INTRODUCTION}

Fibre (lignocellulose) digestion is an anaerobic process in animals and usually takes place in the rumen or hindgut (Mackie, 1997). Several genera of bacteria are

Abbreviations: CEL, cellulolytic counts; DC, direct microscopiccounts; TCC, total culturable counts.

The GenBank accession numbers for the sequences reported in this paper are shown in the Methods section '16S rDNA sequencing'. involved in fibre degradation and it is primarily carried out by Butyrivibrio, Fibrobacter and Ruminococcus spp. Fibrobacter and Ruminococcus spp. are the most fibrolytic, possibly related to their adherent ability, while Butyrivibrio fibrisolvens is a free-floating organism (Weimer, 1996). Phenotypic and phylogenetic analysis of Fibrobacter (Amann et al., 1992; Lin et al., 1994; Lin \& Stahl, 1995; Montgomery et al., 1988; Montgomery \& Macy, 1982) and Butyrivibrio (Forster et al., 1996, 1997) is extensive but the diversity and 
phylogenetic relationships among cellulolytic ruminococci have not been well studied.

Ruminococcus flavefaciens was first isolated by Sijpelsteijn (1951), had a yellow pigment when grown on cellulose, grew in chains on cellobiose, and was weakly Gram-positive. Ruminococcus albus was first isolated by Hungate (1957), but it does not produce a yellow pigment, forms diplococci on cellobiose and is also weakly Gram-positive. The carbohydrate-fermentation and end-product profiles of $R$. flavefaciens and R. albus are almost identical; however, only $R$. flavefaciens produces succinate as one of its major fermentation end products (Hespell et al., 1997).

$16 \mathrm{~S}$ rRNA analysis has provided a framework for evaluating microbial communities without the need for prior cultivation (Amann et al., 1995; Pace, 1997). These studies have provided significant insights into a variety of microbial ecosystems (Pace, 1997), but can only be conducted if probes for target organisms are available. Fibrobacter and Ruminococcus spp. are considered the most important fibrolytic bacteria inhabiting the rumen, and oligonucleotide probes (16S rRNA-based) have been designed for Fibrobacter spp., allowing for a more complete assessment of their ecology (Amann et al., 1992; Lin et al., 1994; Lin \& Stahl, 1995). Oligonucleotide probes designed to the ruminococci tend to be strain specific and do not circumscribe organisms at the species or genus level (Odenyo et al., 1994a, b). $R$. albus and $R$. flavefaciens are major contributors to ruminal fibre degradation and a signature probe that covers these species is essential to further our understanding of their role in rumen ecology.

Estimating population sizes in the rumen is difficult because microbial populations fluctuate dramatically during the day (Hungate, 1966; Leedle et al., 1982). In addition, traditional cultivation techniques (Dehority $e t$ al., 1989) or methods based on Northern blotting of $16 \mathrm{~S}$ rRNA are variable (Raskin et al., 1997). However, a systematic understanding of the size and extent of variation in a microbial ecosystem is critical for efficient experimental design. In ruminal ecology, estimates of variation have been made in relation to culturable count data (Dehority et al., 1989) and an analysis of experimental error associated with various aspects of hybridization studies with rRNA have been obtained (Raskin et al., 1997). However, there are no published data that evaluate the variation obtained with Northernblot analysis of $16 \mathrm{~S}$ rRNA obtained from ruminal studies.

In this paper, $16 \mathrm{~S}$ rDNA RFLP and $16 \mathrm{~S}$ rDNA sequence analyses were conducted to assess the phylogenetic diversity of $R$. albus and $R$. flavefaciens, and sequence information was used to design a 16S rRNA-based oligonucleotide probe. This probe was used to estimate the proportion of $R$. albus and R. flavefaciens in the rumen of adult sheep in a statistically robust manner, and comparisons were made with direct microscopic counts (DC), total culturable counts (TCC) and, total cellulolytic counts (CEL). Variation could be statistically defined and theoretical estimates of samples sizes required to make statistically significant comparisons were calculated.

\section{METHODS}

Isolation and origin of Ruminococcus strains. Tipperary Sanctuary in the Northern Territory of Australia maintains a collection of exotic ruminants, including addax (Addax nasomaculatus), for research purposes. Ruminal contents from an adult addax were obtained by stomach tubing and digesta were deposited into a glass jar. Immediately after collection, $1 \mathrm{ml}$ digesta was injected into a Hungate tube containing either basal medium (see below), $25 \mathrm{mg}$ cellulose discs (see below) and $25 \mathrm{mg}$ dewaxed cotton thread, or basal medium and $50 \mathrm{mg}$ rhodes grass (Chloris gayana). The Hungate tubes were transported to Brisbane, Australia, and the cultures grown to stationary phase at $39^{\circ} \mathrm{C}$. The enrichments on cellulose discs and cotton thread or rhodes grass were maintained by transfer of $200 \mu \mathrm{l}$ culture every $96 \mathrm{~h}$ using an 18-gauge needle, while the enrichment on rhodes grass was transferred every $72 \mathrm{~h}$.

Isolation of cellulolytic bacteria from the addax enrichment was performed according to the roll-tube method of Hungate (1969), but with some modifications. Cellulose roll tubes contained $2 \%(\mathrm{w} / \mathrm{v})$ ball-milled filter paper (Whatman no. 1) and $0.1 \%(\mathrm{w} / \mathrm{v})$ cellobiose in basal medium. Enrichments (cellulose discs plus cotton thread or rhodes grass) were serially diluted in roll tubes and incubated for $5-7 \mathrm{~d}$ at $39^{\circ} \mathrm{C}$. Isolates were checked microscopically for purity and for the ability to grow on cellulose. Unfortunately we were not able to maintain R1-addax ( $R$, rhodes grass enrichment) and $\mathrm{C} 14$ addax ( $C$, cellulose enrichment) as actively growing cultures but were able to retain a DNA sample for sequence analysis.

Fifteen additional bacterial isolates from several geographic regions were analysed (Table 1). A total of ten isolates were from Australia (AR strains, LP-9155, Y1 and the two addax strains), one from Scotland (SY3), one from England (RF1Ba) and the remainder were from North America (Ra8, FD-1, B199, B146 and R13e2). Most of the isolates came from the rumen of cattle and sheep but one (R13e2) was from a reindeer.

Composition of media. The composition of the basal medium was (per litre): $2.5 \mathrm{~g}$ yeast extract, $150 \mathrm{ml}$ clarified rumen fluid, $150 \mathrm{ml}$ mineral- 1 solution $\left[3 \mathrm{~g} \mathrm{~K}_{2} \mathrm{HPO}_{4} .3 \mathrm{H}_{2} \mathrm{O}(100 \mathrm{ml})^{-1}\right]$, $150 \mathrm{ml}$ mineral-2 solution (contains per $100 \mathrm{ml}: 3 \mathrm{~g} \mathrm{KH}_{2} \mathrm{PO}_{4}$, $6 \mathrm{~g}\left(\mathrm{NH}_{4}\right)_{2} \mathrm{SO}_{4}, 6 \mathrm{~g} \mathrm{NaCl}, 1.23 \mathrm{~g} \mathrm{MgSO}_{4} .7 \mathrm{H}_{2} \mathrm{O}, 1.58 \mathrm{~g}$ $\mathrm{CaCl}_{2} \cdot 2 \mathrm{H}_{2} \mathrm{O}$ ), $2 \mathrm{ml}$ trace mineral salts solution (contains per $100 \mathrm{ml}: 0.5 \mathrm{mg} \mathrm{ZnSO} \mathrm{Zn}_{4} .7 \mathrm{H}_{2} \mathrm{O}, 0.15 \mathrm{mg} \mathrm{MnCl}_{2} .4 \mathrm{H}_{2} \mathrm{O}, 1.5 \mathrm{mg}$ $\mathrm{H}_{3} \mathrm{BO}_{3}, 1.0 \mathrm{mg} \mathrm{CoCl}{ }_{2} .6 \mathrm{H}_{2} \mathrm{O}, 0.05 \mathrm{mg} \mathrm{CaCl} .2 \mathrm{H}_{2} \mathrm{O}, 0.1 \mathrm{mg}$ $\left.\mathrm{NiCl}_{2} \cdot 6 \mathrm{H}_{2} \mathrm{O}, 0 \cdot 15 \mathrm{mg} \mathrm{Na} \mathrm{MO}_{4} \cdot 2 \mathrm{H}_{2} \mathrm{O}, 7 \cdot 5 \mathrm{mg} \mathrm{FeCl}{ }_{2} .4 \mathrm{H}_{2} \mathrm{O}\right)$, $3.2 \mathrm{mmol}$ acetic acid, $1.4 \mathrm{mmol}$ propionic acid, $1.1 \mathrm{mmol}$ butyric acid, $1.1 \mathrm{mmol}$ isobutyric acid, $0.31 \mathrm{mmol}$ methylbutyric acid, $0.31 \mathrm{mmol}$ valeric acid, $0.31 \mathrm{mmol}$ isovaleric acid, $2.3 \mathrm{mmol}$ phenylacetic acid, $1 \mathrm{~g}$ L-cysteine $\mathrm{HCl}$ and $0.01 \%$ resazurin. Media were prepared anaerobically according to the methods of Hungate (1950) as modified by Bryant (1972). The medium for total culturable bacteria was similar to the basal medium but with some modifications (Mackie \& Wilkens, 1988). Total cellulolytics were determined by the three-tube most-probable number method (Dehority et al., 1989) with basal medium and cellulose discs as the carbon source. The anaerobic gas was a $95 \% \mathrm{CO}_{2}: 5 \% \mathrm{H}_{2}$ mix, $4 \mathrm{mg} \mathrm{Na}_{2} \mathrm{CO}_{3} \mathrm{ml}^{-1}$ was included as a medium buffer $(\mathrm{pH}$ 6.7). Cellulose discs (Whatman no. 1) were prepared by 
Table 1. Source of Ruminococcus strains used in this study

\begin{tabular}{|c|c|c|}
\hline Strain & Source/host & Source \\
\hline \multicolumn{3}{|c|}{ R. albus strains } \\
\hline B199 & Cow & Marvin Bryant* \\
\hline AR 67 & Sheep & Tom Bauchop $\dagger$ \\
\hline $\mathrm{Ra} 8$ & Cow & Marvin Bryant" \\
\hline SY3 & Sheep & Colin Stewart $\ddagger$ \\
\hline \multicolumn{3}{|c|}{ R. Alavefaciens strains } \\
\hline FD-1 & $\begin{array}{l}\text { Tablet containing } \\
\text { ruminal organisms }\end{array}$ & Marvin Bryant* \\
\hline L.P-9155 & Cattle & Chris McSweeney $\$$ \\
\hline $\mathrm{R} 13 \mathrm{e} 2$ & Reindeer & Burk Dehority\| \\
\hline RF1Ba & Sheep & Colin Orping \\
\hline AR72 & Sheep & Tom Bauchop $\dagger$ \\
\hline AR71 & Sheep & Tom Bauchop $\dagger$ \\
\hline Y1 & Sheep & Geoff Gordon** \\
\hline AR69 & Sheep & Tom Bauchopt \\
\hline AR46 & Sheep & Tom Bauchop $\dagger$ \\
\hline $\mathrm{AR} 47$ & Sheep & Tom Bauchop $\dagger$ \\
\hline B146 & Cow & Marvin Bryant* \\
\hline R1-addax & Addax & This study \\
\hline C14-addax & Addax & This study \\
\hline
\end{tabular}

* University of Illinois, Urbana, USA.

†University of New England, Armidale, Australia.

‡Rowett Research Institute, Aberdeen, UK.

SCSIRO Tropical Agriculture, Indooroopilly, Australia.

| Ohio State University, Columbus, USA.

I AFRC Institute of Animal Physiology and Genetics Research, Babraham, UK.

* CSIRO Animal Production, Prospect, Australia.

incubation (with stirring) at room temperature with phosphoric acid (1M) for at least $1 \mathrm{~h}$. Discs were then rinsed several times with distilled water before use.

Direct microscopic counts (DC). A $1 \mathrm{~g}$ ruminal sample was diluted 10-fold with anaerobic diluent (Mackie \& Wilkens, 1988) and vortexed for $1 \mathrm{~min}$. The diluted sample was placed in a counting chamber and cell numbers were converted to cells per $\mathrm{ml}$ by multiplying by $2 \times 10^{8}$.

165 rDNA amplification. The 165 rDNA was amplified from a $1 / 100$ dilution of stationary phase culture with universal primers $27 f$ (5'-AGAGTTTGATCMTGGCTCAG-3') and 1492r (5'-TACGYTACCTTGTTACGACT-3'). PCR reactions contained (per $20 \mu \mathrm{l}$ ) $2 \mu \mathrm{l} 10 \times$ PCR buffer, $0 \cdot 2 \mu \mathrm{l}$ $\mathrm{MgCl}_{2}(250 \mathrm{mM}), 0.4 \mu \mathrm{l}$ dNTPs $(10 \mathrm{mM}), 10 \mathrm{pmol}$ each primer, $1 \mathrm{U}$ Taq polymerase (Promega) and $0.5 \mu \mathrm{l} 1 / 100$ dilution of culture. Cycling conditions were one cycle of $94^{\circ} \mathrm{C}$ for $5 \mathrm{~min}, 60^{\circ} \mathrm{C}$ for $1 \mathrm{~min}$ and $72{ }^{\circ} \mathrm{C}$ for $90 \mathrm{sec}$, then $31 \mathrm{cycles}$ of $94^{\circ} \mathrm{C}$ for $1 \mathrm{~min}, 50^{\circ} \mathrm{C}$ for $1 \mathrm{~min}$ and $72{ }^{\circ} \mathrm{C}$ for $90 \mathrm{sec}$. The final cycle was $94^{\circ} \mathrm{C}$ for $1 \mathrm{~min}, 50^{\circ} \mathrm{C}$ for $1 \mathrm{~min}$ and $72{ }^{\circ} \mathrm{C}$ for $8 \mathrm{~min}$.

Restriction digests. Approximately $100 \mathrm{ng} 16 \mathrm{~S}$ rDNA PCR product was digested with restriction enzymes for at least $2 \mathrm{~h}$ according to the manufacturer's instructions. Fifteen microlitres of the restricted product was electrophoresed on a $1 \%$ (0.5 $\times$ TBE) agarose gel.
$16 S$ rDNA sequencing. Nearly complete 165 rDNA sequence data were obtained for (GenBank accession numbers are shown in parentheses) $R$. flavefaciens AR46 (AF104837), $R$. flavefaciens R1-addax (AF104835), R. flavefaciens C14-addax (AF104834), R. flavefaciens Y1 (AF104846), R. flavefaciens AR72 (AF104841), $R$. flavefaciens FD-1 (AF104844), $R$. albus Ra8 (AF104833) and $R$. albus AR67 (AF104839). Approximately the first $462 \mathrm{bp}$ from the $5^{\prime}$ end were sequenced for the remaining strains (GenBank accession numbers are shown in parentheses); R. flavefaciens B146 (AF104842), R. flavefaciens AR47 (AF104838), R. flavefaciens AR69 (AF104840), R. flavefaciens R13e2 (AF104847), R. flavefaciens LP-9155 (AF104836), R. albus B199 (AF104843) and R. albus SY3 (AF104845).

Concentrations of DNA after PCR amplification were measured by image analysis (Kodak BioMax 1D) of ethidiumbromide-stained agarose gels and approximately $25 \mathrm{ng}$ of each product was included in a $20 \mu \mathrm{l}$ sequencing reaction. Sequences were obtained in both orientations from at least two separate PCR products using universal primers (Ash et al, 1993). All reactions were carried out with the ABI Prism cycle sequencing kit (Applied Biosystems) and gels were run on an $\mathrm{ABI}$ automated sequencer (Applied Biosystems).

Phylogenetic analysis. Restriction fragments were sized and coded as the presence (1) or absence $(0)$ of unique bands. 
These binary-coded characteristics were analysed by the Dollop procedure (Farris, 1977) using the PHYLIP computer program (Felsenstein, 1993).

Sequence data were aligned with CLUSTAL w (Thompson $e t$ al., 1994) and the following alignment strategy was followed for complete and partial sequences. (i) Nearly complete sequences of ruminococci obtained in this study were aligned with nearly complete sequences of highly similar ( $>90 \%$ similarity) organisms (not ruminococci) found in the Ribosomal Database Project (Maidak et al., 1997). (ii) Sequences were manually adjusted with reference to secondary structure providing a robust template alignment. (iii) Partial sequences were added to the template alignment iteratively using the profile alignment procedure available on CLUSTAL W (Thompson et al., 1994).

Phylogenetic analysis was by the distance method of Jukes \& Cantor (1969) and tree topology was inferred by the neighbour-joining algorithm (Nei \& Li, 1979) with TREECON software (Van de Peer \& De Wachter, 1994). All sequencebased trees were analysed by bootstrapping of 1000 trees. The phylogenetic analysis was checked by using the maximumlikelihood method available on PHYLIP (Felsenstein, 1993).

Design of $16 \mathrm{~S}$ rRNA oligonucleotide probes. A signature probe for $R$. albus and $R$. flavefaciens was designed and is designated with a 'IV' (S-G-Rum IV-0132-a-A-17; 5'-TGKTAATACCYCATAAY-3') to differentiate it from cluster XIVa ruminococci (Collins et al., 1994). The wash temperature was determined experimentally as $34^{\circ} \mathrm{C}$ with $1 \times$ SSC $(0.15 \mathrm{M}$ $\mathrm{NaCl}, 0 \cdot 015 \mathrm{M}$ sodium citrate). The probe sequences were checked for specificity with the CHECK-PROBE procedure on the Ribosomal Database Project (Maidak et al., 1997) and assessed empirically by hybridization to target ruminococci as well as a diverse set of ruminal bacteria (see Table 2).

DNA extraction. A $1 \mathrm{ml}$ sample from an in vitro culture was centrifuged $(10000 \mathrm{~g})$ for $5 \mathrm{~min}$, the supernatant removed and the pellet resuspended in $1 \mathrm{ml} 100 \mathrm{mM}$ Tris $/ \mathrm{HCl}$ (pH 8), $10 \mathrm{mM}$ EDTA, $0.2 \mathrm{ml} 10 \%$ SDS and $0.1 \mathrm{ml}$ proteinase $\mathrm{K}$ (10 $\mathrm{mg} \mathrm{ml}^{-1}$ ), and incubated at $55^{\circ} \mathrm{C}$ for $2 \mathrm{~h}$. After the sample was divided in two (approx. $0.65 \mathrm{ml}$ each), $0.12 \mathrm{ml} 5 \mathrm{M} \mathrm{NaCl}$ and $0.065 \mathrm{ml}(10 \%)$ hexadecyltrimethylammonium bromide (CTAB) were added to each tube prior to incubation at $65^{\circ} \mathrm{C}$ for $10 \mathrm{~min}$. Each sample was extracted with $0.7 \mathrm{ml}$ chloroform/isoamyl alcohol $(24: 1)$ and centrifuged $(10000 \mathrm{~g})$ for $15 \mathrm{~min}$. The supernatant was removed and mixed with $0.225 \mathrm{ml} 5 \mathrm{M}$ ammonium acetate and $0.55 \mathrm{ml} 100 \% 2$-propanol, incubated on ice for $1 \mathrm{~h}$ and centrifuged $(10000 \mathrm{~g})$ for $15 \mathrm{~min}$ and the supernatant aspirated. The DNA pellet was washed with cold $70 \%$ ethanol, dried under vacuum and resuspended in TE buffer $(0 \cdot 1 \mathrm{ml})$ containing $5 \mu \mathrm{g} \mathrm{RNase} \mathrm{ml}{ }^{-1}$ (Boehringer Mannheim). The DNA suspension was loaded onto a Wizard DNA clean up column (Promega) and the eluted DNA $(50 \mu l)$ was used in PCR reactions.

RNA extraction. A $1 \mathrm{ml}$ sample of ruminal digesta was taken with a P1000 pipette with the tip cut off so that sufficient plant material was included in the sample. The RNA was extracted by $5 \mathrm{~min}$ of bead-beating according to the procedure of Stahl et al. (1988).

Probe hybridization protocol. Oligonucleotide labelling with digoxigenin and hybridizations were carried out as previously described (Krause \& Russell, 1996). The RNA concentration was measured spectrophotometrically and adjusted to $100 \mathrm{ng} \mu \mathrm{l}^{-1}$. Three volumes $2 \%$ glutaraldehyde were added to the RNA and allowed to denature for $10 \mathrm{~min}$ at $25^{\circ} \mathrm{C}$. Before application to positively charged nylon membranes (Boeh- ringer Mannheim) a volume equaling $1 \mu \mathrm{g}$ per slot was diluted with $0.0002 \%$ bromophenol blue and $1 \mu \mathrm{g}$ polyadenylic acid $\mathrm{ml}^{-1}$. One microgramme of RNA was applied to nylon membranes, and the membranes were baked at $120^{\circ} \mathrm{C}$ for 30 min. The membranes were prehybridized with hybridization solution [ $25 \%$ formamide, $5 \times \mathrm{SSC}, 50 \mathrm{mM} \mathrm{Na}{ }_{2} \mathrm{HPO}_{4}, 2 \%$ blocking reagent (Boehringer Mannheim), $2 \%$ SDS, $0.1 \% \mathrm{~N}$ lauroylsarcosine] for at least $2 \mathrm{~h}$. Digoxigenin (Boehringer Mannheim) labelled probe $\left(10 \mathrm{ng} \mathrm{ml}^{-1}\right)$ was added to the hybridization solution and allowed to hybridize overnight. The membranes were then washed at the appropriate stringency for each probe with $1 \times$ SSC. Membranes were subsequently processed according to the manufacturer's instructions (Boehringer Mannheim). Total bacterial 16S rRNA was determined by hybridization with a universal eubacterial probe S-D-Bact-0338-a-A-18 (Amann et al., 1990).

Animal experiments. Animal experiments had the following objectives. (1) To establish a steady-state population in the rumen so that baseline statistical variation in microbial populations could be assessed using traditional and $16 \mathrm{~S}$ rRNA based methods. This was accomplished by feeding sheep eight equal-sized meals within a $24 \mathrm{~h}$ period using automated feeders. (2) A common rumen sample would be used for estimation of the relative abundance of cellulolytic bacteria using traditional and $16 \mathrm{~S}$ rRNA based methods. (3) Variance analysis could be conducted on data to determine sample sizes required to obtain statistically significant differences when $16 \mathrm{~S}$ rRNA slot-blotting is used to study ruminal populations.

Three adult sheep were fistulated (McSweeney, 1989) and housed in metabolism crates. Eight-times-per-day automated feeders were used to provide feed to animals on a continuous basis during a $24 \mathrm{~h}$ period. Sheep were fed a rhodes grass diet augmented with 50 of a protein supplement. The sheep had free access to water $24 \mathrm{~h}$ per day. Ruminal samples were taken $1 \mathrm{~h}$ after the $10 \mathrm{am}$ feeding. All animal experimental procedures were approved and monitored by an institutional animal ethics committee.

Statistical analysis. All statistical analyses were done with Statistica 5.0 software. The experimental unit consisted of three animals for each point. Data were analysed using analysis of variance procedures and treatment means were compared using orthe zonal comparisons. Bacterial count data did not have homogeneous variances and were transformed using a log transformation procedure. Determination of sample sizes was according to Snedecor \& Cochran (1980). The following formula was used:

$$
n=\left(\mathrm{Z}_{\alpha}+\mathrm{Z}_{\beta}\right)^{2} \sigma_{\mathrm{D}}^{2} / \delta^{2}
$$

where $n$ is the number of samples required, $Z$ is the standard normal deviate, $\alpha$ and $\beta$ are the probabilities that the standard normal deviate will lie within the specified normal distribution, $\sigma$ is the standard deviation determined by experimentation and is critical in determining the sample size; if the variation increased, so does the number of samples required, and $\delta$ is the power of the test: the probability of showing a true difference between treatments of a specified size (usually 80 or $90 \%$ ).

\section{RESULTS}

\section{Analyses based on 16S rDNA RFLP analysis}

Enterobacterial repetitive intergenic consensus, repetitive extragenic palindromic, and 16S-23S rDNA spacer 


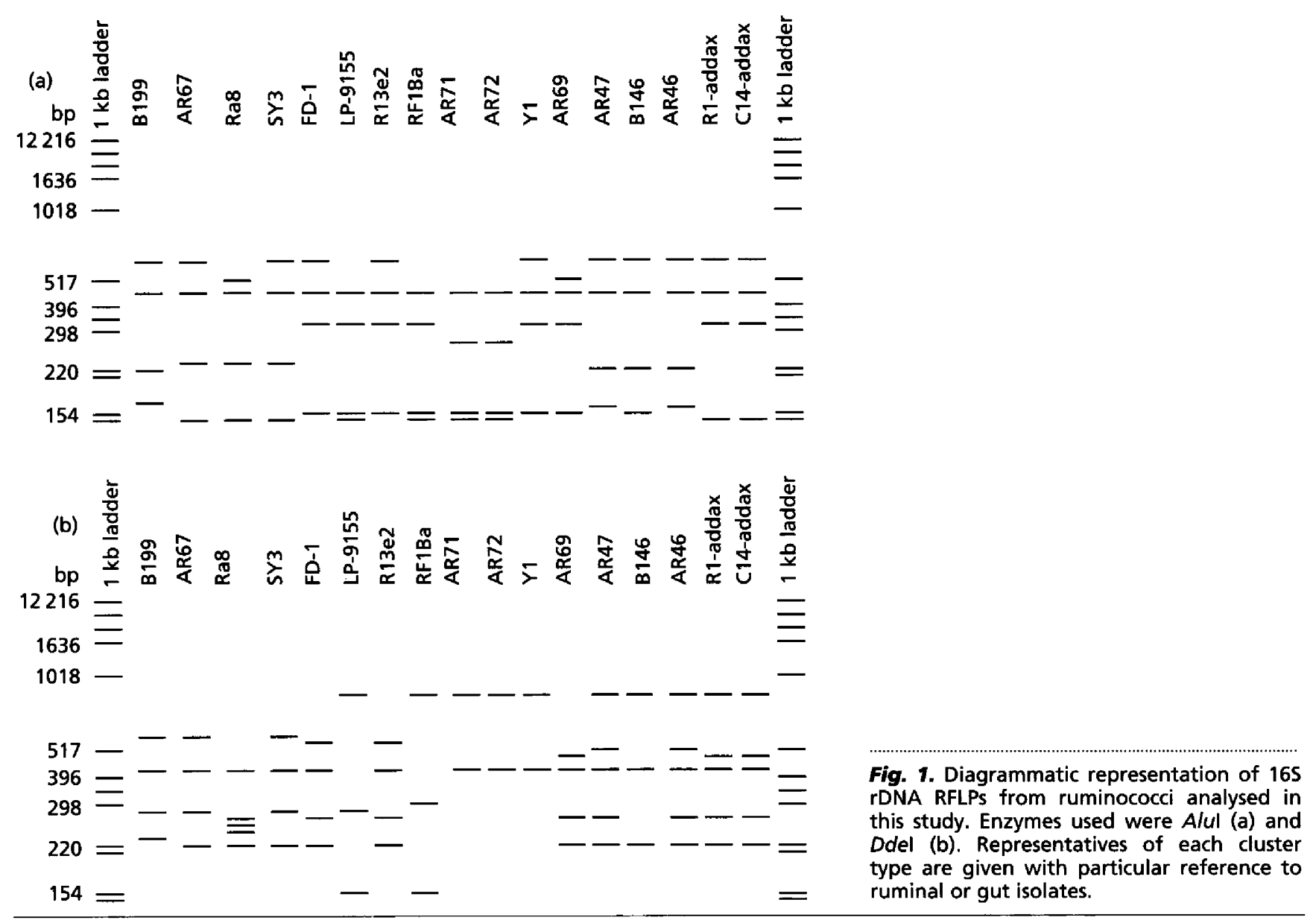

polymorphisms have previously indicated that the Ruminococcus isolates used in this work are genetically distinct (Krause et al., 1999). Restriction enzymes were selected that would differentiate between strains of ruminococci and were not selected with phylogenetic analysis in mind. AluI, DdeI, HincI, Hinfl, HpaII, MboI, MseI and Sau3AI were initially assessed but AluI and $D d e I$ were the most useful in differentiating strains. $D d e$ I fragments were particularly effective in differentiating between $R$. albus and $R$. flavefaciens, and $A l u \mathrm{I}$ was useful in separating closely related strains. Restriction enzymes were used to estimate a preliminary phylogeny (Fig. 1) and R. flavefaciens and R. albus were grouped separately. All strains except AR71 and RF1Ba were sequenced.

$16 \mathrm{~S}$ rDNA RFLP analysis was useful in determining culture purity prior to sequence analysis. FD-1, AR71, AR72, AR46, R13e2 and $\mathrm{Y} 1$ were contaminated and $16 \mathrm{~S}$ rDNA RFLP gave bands adding up to more than $1500 \mathrm{bp}$. These strains were streaked on cellobiose agarose plates, then well-separated colonies were selected and transferred to cellulose medium to check for ability to degrade cellulose.

Several methods of phylogenetic analysis using restric-

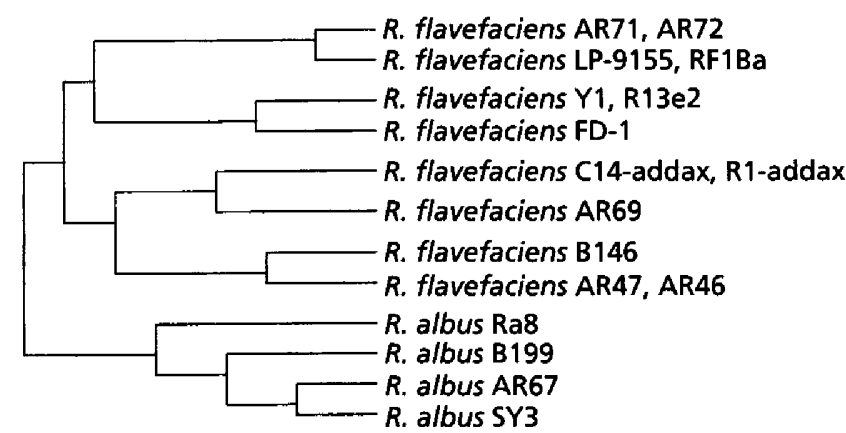

Fig. 2. Cluster analysis derived from $16 \mathrm{~S}$ rDNA RFLPs of Ruminococcus strains digested with Alul and Ddel.

tion-character data were used but all gave widely different tree topologies. However, the Dollop procedure (Farris, 1977) produced a tree most similar to that derived from sequence analysis (Fig. 2). Dollop analysis of restriction fragments (Fig. 1) separated $R$. albus and $R$. flavefaciens into two clusters. In the $R$. 


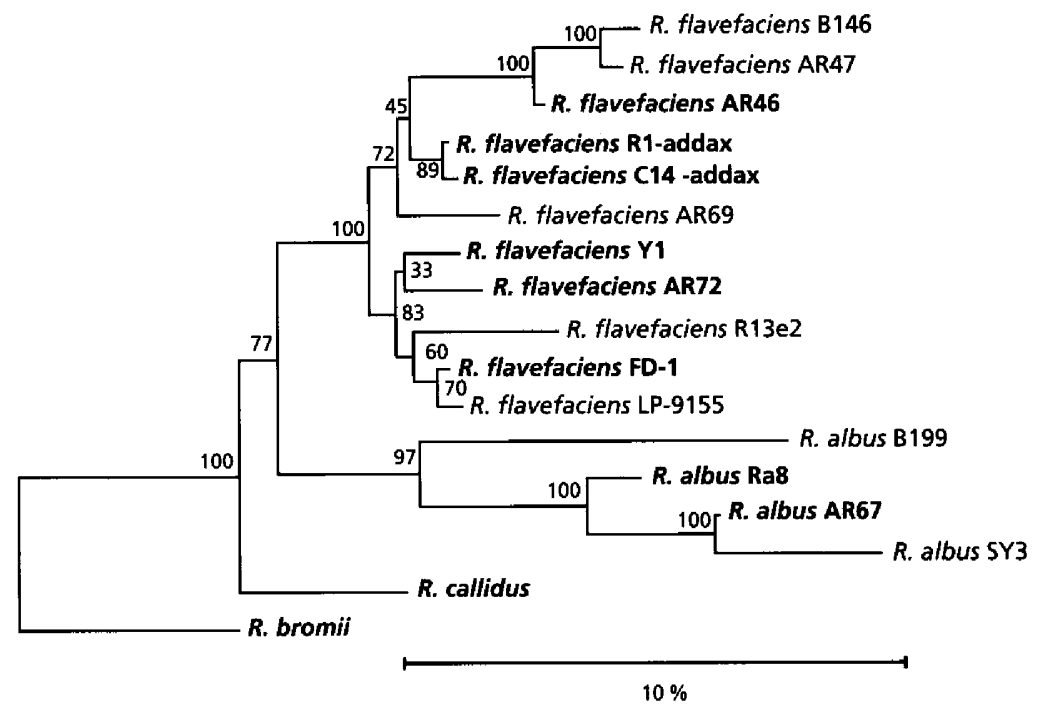

Fig. 3. Phylogenetic relationships among Ruminococcus sequences in this study. Nearly complete sequences are in bold. Bootstrap values are expressed as a percentage of 1000 random trees. The scale represents 0.1 mutations per site and is represented as a percentage.

flavefaciens cluster, two major groups could be defined; strains AR71, AR72, R13e2, LP-9155 and RF1Ba in one group, and R1-addax, C14-addax, AR69, B146, AR46, Y1 and FD-1 in another group. This second cluster could be subdivided into two further groups, the largest of which included the Addax isolates. Based on this preliminary analysis, only strains that were obviously different were sequenced.

\section{5 rDNA sequence analysis}

Nearly complete sequence data were obtained for strains AR67, Ra8, FD-1, AR72, Y1, C14-addax, R1-addax and AR46. Partial sequence of the first $462 \mathrm{bp}$ from the $5^{\prime}$ end was obtained for strains SY3, B199, LP-9155, R13e2, AR69, AR47 and B146, but RF1Ba and AR71 were not sequenced. Similarity analysis placed all strains within $R$. albus or $R$. flavefaciens and the closest relative was Ruminococcus callidus (Fig. 3). Among $R$. albus strains, sequence similarity (462 bp) was at least $87.4 \%$, and $89.8 \%$ among $R$. flavefaciens. $R$. callidus was more closely related to $R$. flavefaciens (mean similarity, $88.7 \%$ ) than to $R$. albus (mean similarity, $83.9 \%$ ). Ruminococcus bromii is a non-cellulolytic Ruminococcus sp. that is closely related to $R$. flavefaciens and $R$. albus, with a mean sequence similarity of $79 \cdot 3 \%$. Phylogenies were estimated using the neighbour-joining method and bootstrap analysis tested the robustness of tree nodes (Fig. 3). The phylogeny was relatively robust (bootstrap values between 90 and 95 ) but several nodes were notably weak: FD-1 and LP-9155, and Y1 and AR72.

\section{S rRNA oligonucleotide probes}

Oligonucleotide probes could be designed that were highly specific for cluster IV Ruminococcus spp. (referred to as Ruminococcus IV). The $16 \mathrm{~S}$ rRNA oligonucleotide probe designed (S-G-Rum IV-0132-a-A-
17) was highly specific for R. albus and R. flavefaciens, had little identity with cluster XIVa ruminococci, and did not result in significant hybridization to a group of phylogenetically diverse ruminal and non-ruminal bacteria (Table 2).

\section{Experiments with adult sheep}

Total numbers of bacteria in the rumen were measured as the DC $\left[1.6 \times 10^{10}(\mathrm{~g} \text { digesta })^{-1}\right]$ or total culturable counts [TCC; $9.6 \times 10^{9} \mathrm{~g}$ digesta $)^{-1}$ ], and did not vary significantly $(P<0 \cdot 05)$ on a daily basis (Table 3$)$. Total cellulolytic (CEL) most-probable numbers averaged $0.5 \times 10^{9}$ (g digesta) $^{-1}$ (Table 3). Ruminococcus IV (S-GRum IV-0132-a-A-17) made up 1.6\% of the population and F. succinogenes (S-S-F.succ-0650-a-A-20) $1.8 \%$ (Table 3). Together, Ruminococcus IV plus F. succinogenes made up $4.0 \%$ of the eubacterial population. CEL were $3.1 \%$ of the DC and different $(P>0.1)$ from Ruminococcus IV plus $F$. succinogenes $(4.0 \%)$, and Ruminococcus IV plus $F$. succinogenes was different $(P$ $<0 \cdot 1)$ when CEL were expressed as a proportion of the $\operatorname{TCC}(5 \cdot 2 \%)$.

Base-line variance $\left(\sigma^{2}\right)$ for a number of parameters was determined by analysing sheep ruminal samples on six separate days (spread over a $24 \mathrm{~d}$ period) from three sheep. The data over the $24 \mathrm{~d}$ period varied (expressed as CV) as little as $14.5 \%$ for the TCC, and as much as $50.5 \%$ for CEL/TCC (Table 4). The cVs for $16 \mathrm{~S}$ rRNA based analyses were fairly large and were approximately $40 \%$. This variance was used to determine how many samples would be required to detect a $20 \%$ difference between treatments at the $95 \%$ confidence interval and for most parameters was four samples. In a hypothetical experiment with $50 \%$ more variation (ad libitum feeding), generally only one more sample is required if the same statistical criteria are applied (Table 4). 
Table 2. Hybridization of 165 rRNA probes to a phylogenetically diverse group of bacteria

\begin{tabular}{|c|c|c|}
\hline Bacterial strain & $\begin{array}{l}\text { S-D-Bact- } \\
\text { 0338-a-A-18 }\end{array}$ & $\begin{array}{l}\text { S-G-Rum } \\
\text { IV-0132-a-A-17 }\end{array}$ \\
\hline R. flavefaciens AR71 & + & + \\
\hline R. flavefaciens AR72 & + & + \\
\hline R. flavefaciens $\mathrm{R} 13 \mathrm{e} 2$ & + & + \\
\hline R. flavefaciens LP-9155 & + & + \\
\hline R. flavefaciens $\mathrm{RF} 1 \mathrm{Ba}$ & + & + \\
\hline R. flavefaciens R1-addax & + & + \\
\hline R. flavefaciens C14-addax & + & + \\
\hline R. flavefaciens AR69 & + & + \\
\hline R. flavefaciens $\mathrm{B} 146$ & + & + \\
\hline R. flavefaciens AR 46 & + & + \\
\hline R. flavefaciens AR47 & + & + \\
\hline R. flavefaciens $\mathrm{Y} 1$ & + & + \\
\hline R. flavefaciens FD-1 & + & + \\
\hline R. albus B199 & + & + \\
\hline R. albus $\mathrm{Ra} 8$ & + & + \\
\hline R. albus AR67 & + & + \\
\hline R. albus SY3 & + & + \\
\hline R. callidus ATCC 27760 & + & - \\
\hline R. bromii ATCC 27255 & + & - \\
\hline B. fibrisolvens $\mathrm{OB} 156$ & + & - \\
\hline B. fibrisolvens $\mathrm{H} 17 \mathrm{c}$ & + & - \\
\hline Escherichia coli & + & - \\
\hline Eubacterium cellulosolvens 5494 & + & - \\
\hline Eubacterium ruminantium GA195 & + & - \\
\hline F. succinogenes $\$ 85$ & + & - \\
\hline Lactobacillus vitulinus B26 & + & - \\
\hline Megasphaera elsdenii & + & - \\
\hline Prevotella ruminicola 23 & + & - \\
\hline Prevotella ruminicola GA33 & + & - \\
\hline Ruminobacter amylophilus 70 & + & - \\
\hline Selenomonas ruminantium HD4 & + & - \\
\hline Streptococcus bovis JB1 & + & - \\
\hline Streptococcus bovis $\mathrm{K} 11$ & + & - \\
\hline Succinomonas amylolytica $\mathrm{B}_{2} 4$ & + & - \\
\hline Succinovibrio dextrinosolvens 22B & + & - \\
\hline Treponema bryantii $\mathrm{B}_{2} 5$ & + & - \\
\hline
\end{tabular}

Table 3. Cellulolytic bacterial populations in adult sheep determined by cultivation or 165 rRNA oligonucleotide probes

The following comparisons are significantly different $(P<0.05)$ : DC vs TCC, CEL/DC vs CEL/TCC. Comparison between Ruminococcus IV $+F$. succinogenes and CEL/TCC is also different $(P<0 \cdot 1)$. The sample size was six for all determinations.

\begin{tabular}{|c|c|c|c|c|c|c|c|c|}
\hline \multirow[t]{3}{*}{ Item } & \multirow{2}{*}{\multicolumn{3}{|c|}{$\begin{array}{c}\text { Microscopic and } \\
\text { culturable counts } \\
{\left[\times 10^{-9}(\mathrm{~g} \text { digesta })^{-1}\right]}\end{array}$}} & \multicolumn{2}{|c|}{$\begin{array}{c}\text { Proportion CEL } \\
(\%)\end{array}$} & \multicolumn{3}{|c|}{$\begin{array}{c}\text { 16S rRNA oligonucleotide } \\
\text { probes }(\%)^{*}\end{array}$} \\
\hline & & & & \multirow{2}{*}{ CEL/DC } & \multirow{2}{*}{ CEL/TCC } & \multirow{2}{*}{$\begin{array}{l}\text { Ruminococcus } \\
\text { IV }\end{array}$} & \multirow{2}{*}{ F. succinogenes } & \multirow{2}{*}{$\begin{array}{l}\text { Ruminococcus IV }+ \\
\text { F. succinogenes }\end{array}$} \\
\hline & DC & TCC & CEL & & & & & \\
\hline Mean & $16 \cdot 3$ & $9 \cdot 6$ & 0.5 & $3 \cdot 1$ & $5 \cdot 2$ & $2 \cdot 2$ & 1.8 & $4 \cdot 0$ \\
\hline SD & 3.9 & 1.4 & $0 \cdot 2$ & 1.5 & $2 \cdot 6$ & 0.7 & 0.7 & $1 \cdot 0$ \\
\hline
\end{tabular}

"Relative abundance of Ruminococcus IV (S-G-Rum IV-0132-a-A-17) and F. succinogenes (S-S-F.succ-0650-a-A-20) expressed as a proportion of eubacteria (S-D-Bact-0338-a-A-18). 
Table 4. Sample size required to determine statistically significant differences between treatments

Raw data used to calculate means is shown in Table 3. All abbreviations are the same as Table 3.

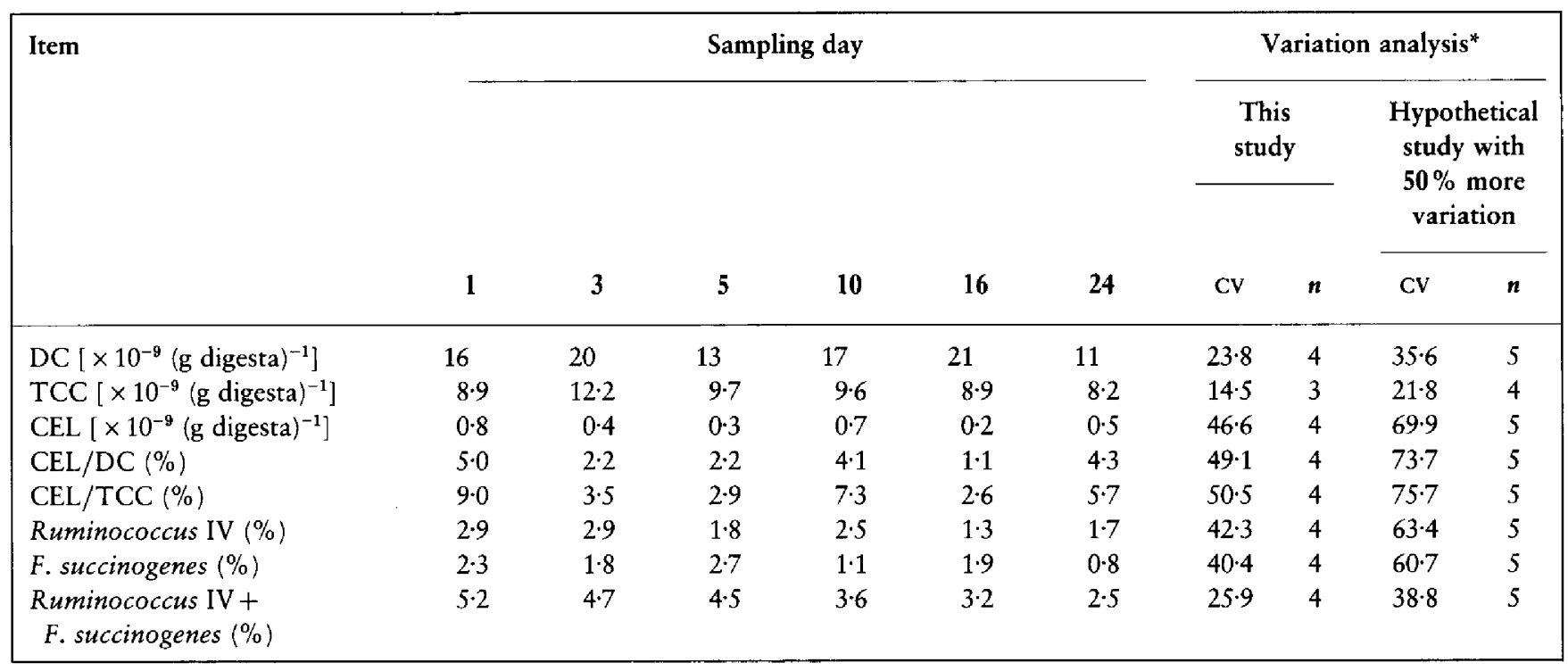

*Sample size required to detect a $20 \%$ difference with $95 \%$ confidence.

\section{DISCUSSION}

Phenotypically, the genus Ruminococcus includes several isolates from gastrointestinal environments (Hespell et al., 1997). In the rumen $R$. albus and R. flavefaciens are usually the predominant species, while $R$. bromii, $R$. callidus, Ruminococcus torques, Ruminococcus gnavus, Ruminococcus lactaris and Ruminococcus obeum are usually isolated from the hind-gut of non-ruminants (Bryant, 1986). Previous studies (Rainey \& Janssen, 1995; Willems \& Collins, 1995) have indicated that the ruminococci are polyphyletic and form two main groups within the clostridia (Collins et al., 1994): cluster IV represented by $R$. flavefaciens but also including $R$. albus, R. bromii, and $R$. callidus and cluster XIVa encompassing $R$. torques, $R$. gnavus, $R$. lactaris and $R$. obeum. However, these studies (Rainey \& Janssen, 1995; Willems \& Collins, 1995) only sequenced one strain of each of $R$. albus and $R$. flavefaciens.

The genus Ruminococcus falls within the Peptococcaceae, which is a family of anaerobic Gram-positive cocci comprising five genera; Peptococcus, Peptostreptococcus, Ruminococcus, Sarcina and Coprococcus (Ezaki et al., 1994). Ruminococcus is phenotypically distinguishable from other Peptococcaceae by the presence of meso-diaminopimelic acid at position three in the peptidoglycan (Ezaki et al., 1994), but additional informative phenotypic characteristics appear to be lacking. All strains sequenced in this study were ruminal isolates and $16 \mathrm{~S}$ rDNA sequence analysis placed these organisms into cluster IV of the clostridia (Collins et al., 1994). R. callidus was originally isolated from the hindgut of a human (Holdeman \& Moore, 1974), and is most closely related to R. flavefaciens. R. bromii is a noncellulolytic, starch-fermenting Ruminococcus that has been isolated from the rumen and hind-gut (Bryant, 1986).

It is interesting to note that the hind-gut isolates are predominantly in cluster XIVa (Collins et al., 1994) and suggest an ecological and phylogenetic division within ruminococci isolated from the gastrointestinal tract. In the case of Fibrobacter, all strains had similar phenotypes but $F$. succinogenes could be subdivided on the basis of $16 \mathrm{~S} \mathrm{rDNA}$ sequence data and ecological niche (F. succinogenes, rumen; $F$. intestinalis, hind-gut). This apparent phylogenetic and ecological distinction between ruminococci is a basis for further work to define consensus phenotypes that could be used as a basis for reclassification of currently described Ruminococcus species.

The monophyletic nature of $R$. albus and $R$. flavefaciens made it possible to design an oligonucleotide probe that covered all strains but excluded the closely related species $R$. bromii and $R$. callidus. This oligonucleotide probe also excluded all cluster XIVa Ruminococcus spp. An important aspect of oligonucleotide design is that it provides a hierarchical approach for comparing culturable and uncultured diversity. Oligonucleotide probes can be used to determine the relative abundance of a particular species (Lin et al., 1994; Lin \& Stahl, 1995) or groups of organisms at higher levels of hierarchal complexity such as kingdoms or domains (Fry $e t a l ., 1997$ ). If a set of probes with increasing levels of hierarchical complexity are used on the same sample, an estimate of undescribed diversity can be obtained (Lin et al., 1994; Lin \& Stahl, 1995). Ruminal bacteria enriched on cellulose medium should be composed mainly of Ruminococcus and Fibrobacter as these are the major cellulolytic species [Butyrivibrio is xylanolytic (Hespell et al., 1997; Hungate, 1966)] and relative 
abundances determined with $16 \mathrm{~S}$ rDNA probes should provide some evidence of the extent of diversity circumscribed by the probes.

Published literature (see reviews by Dehority \& Orpin, 1988; Hungate, 1966) indicates that the TCC in the rumen is usually $12-80 \%$ of the direct count. These studies demonstrated that a large proportion of ruminal diversity could be cultured, unlike that in many other environments where only $0 \cdot 1-10 \%$ is culturable (Head et al., 1998; Pace, 1997). Values obtained were: $1.6 \times 10^{10} \mathrm{ml}^{-1}$ for the DC, $9.6 \times 10^{9} \mathrm{ml}^{-1}$ for the TCC and $5 \times 10^{8} \mathrm{ml}^{-1}$ for the CEL count. The TCC was $58.9 \%$ of the DC and the CEL count was $3.1 \%$ of the DC or $5.2 \%$ of the TCC (Table 3). Although the medium used for the enumeration of the TCC cultivates most of the important ruminal bacteria, there are some groups that are not enriched. Notable exceptions are: (1) methanogens, which can make up $3-5 \%$ of the population and require a hydrogen head-space for growth (Lin et al., 1996), (2) slow-growing obligate amino-acid fermenting bacteria that are approximately $1 \%$ of the population (Chen \& Russell, 1989; Yang \& Russell, 1993), and (3) protozoa. These considerations have important implications when $16 \mathrm{~S}$ rRNA oligonucleotide probe data are interpreted (see below).

Even though traditional methods for enumerating micro-organisms suffer from cultivation bias, they provide a useful framework within which to compare $16 \mathrm{~S}$ rRNA based data. 16S rRNA analysis with the Ruminococcus IV probe indicated that their relative abundance was $2 \cdot 2 \%$, and probing with the $F$. succinogenes probe gave a relative abundance of $1.8 \%$ (Fig. 3 ). The values for $F$. succinogenes are similar to those reported in the literature using $16 \mathrm{~S}$ rRNA analysis (Lin et al. 1994), and cultivation-based numbers for Ruminococcus and Fibrobacter are between 2 and $10 \%$, depending on the diet (Dehority \& Orpin, 1988; Hespell et al., 1997; Stewart \& Flint, 1989). Therefore, within the context of the published literature, the relative abundance of the ruminococci estimated with the Ruminococcus IV probe is reasonable, but the probe is unlikely to cover all the natural diversity represented by $R$. albus and $R$. flavefaciens.

Ruminococcus IV $+F$. succinogenes was $4 \%$ of the TCC, but significantly different $(P<0 \cdot 1)$ from the total CEL $(5 \cdot 2 \%$ of TCC). This difference was $23 \%$ and several factors may have resulted in this discrepancy including the following. (1) Oligonucleotide probes for the $F$. succinogenes and Ruminococcus in this study have been designed from sequence obtained from cultured bacteria. Possible uncultured bacteria may not be covered by the probe sequences. A clone library of the addax consortia revealed Ruminococcus sequences that were not homologous to sequences of cultured bacteria (unpublished data). However, the Ruminococcus IV probe would have hybridized with these isolates. (2) The cellulolytic count probably contains non-cellulolytic bacteria. It is well known that some ruminal bacteria can feed on breakdown products (cellodextrins) of cellulose (Russell, 1985) resulting in an artificially high CEL count. (3) The TCC does not include all ruminal micro-organisms but the universal probe used to normalize the blots would include these organisms. Even though there are obvious flaws with the comparisons made, what is apparent is that the probes employed cover a significant amount of the cultured diversity of ruminal cellulolytic bacteria. The Ruminococcus IV probe in particular is a valuable tool for use in ecological studies and provides relative abundance values that are in accordance with present knowledge of the ecology of the rumen.

Molecular ecological analyses of microbial ecosystems is a new and emerging field, and over the last 10 years there has been a large emphasis on the development of new and improved techniques (Stackebrandt \& Goebel, 1994; Suzuki \& Giovannoni, 1996; Van De Peer et al., 1994; Wagner et al., 1994; Zheng et al., 1996). To date, the vast majority of studies which employ these techniques have been descriptive and little quantitative and statistical rigour has been applied. In contrast, macroecological studies utilize statistical methods extensively to interpret processes and populations (Link \& Sauer, 1998). One of the most fundamental aspects of experimental design is an understanding of the amount of variation inherent in the ecosystem studied and the techniques used. An estimate of the variation with $16 \mathrm{~S}$ rRNA determined populations has not to our knowledge been conducted on ruminal samples. However, Raskin et al. (1997) have made a systematic study of the variation associated with $16 \mathrm{~S}$ rRNA slot blotting.

Baseline variation was determined by obtaining cultivation and $16 \mathrm{~S}$ rRNA based data on steady-state ruminal populations. The $\mathrm{CV}$ for $16 \mathrm{~S}$ rRNA based data was as high as $42.3 \%$ and in most cases was similar to that obtained with cultivation techniques (Table 4). This variance is used to calculate sample sizes required to obtain statistical differences. In this study, four samples are required to detect a $20 \%$ difference with statistical significance (95\% confidence interval), but this increased to approximately five samples when sheep were fed ad libitum [hypothetical example; $50 \%$ increase in variance estimated from literature (Leedle $e t$ al., 1982)] (Table 4). These data provide a basis for the design of rumen ecological experiments for other investigators. If, for example, an investigator wishes to detect a $10 \%$ decline in a rumen bacterial population using $16 \mathrm{~S}$ rRNA probes, the variance associated with the technique determined in this study could be used to calculate the sample size: six samples to obtain a significant difference at the $95 \%$ confidence interval.

From our data, and the examples given above it appears that four to six samples would be adequate for most purposes, irrespective of whether the animals are fed ad libitum or not. The likely reason is that variation associated with slot-blot analysis of rRNA is high, and instead of taking more samples, effort should be put into decreasing the error associated with blotting. Raskin $e t$ al. (1997) systematically assessed this issue and suggested 
that the majority of the variation is due to the stringency washes and membrane properties.

In conclusion, this study has shown that Ruminococcus within cluster IV of the clostridia are monophyletic and the ruminal species can be placed into either $R$. albus or $R$. flavefaciens. An important feature of this work is that an oligonucleotide probe for cluster IV ruminococci was designed and tested, and that a significant proportion of the Ruminococcus diversity is covered by the probe. It is, however, clear that there is likely to be undescribed Ruminococcus diversity not covered by the Ruminococcus IV probe. The Ruminococcus IV and F. succinogenes probes were used to describe the variation in steady-state ruminal populations and the number of samples required to obtain statistically significant differences between treatments could be calculated.

\section{ACKNOWLEDGEMENTS}

This research was partially supported by the Australian Meat and Livestock Authority. The technical support of $\mathrm{Mr}$ Rowan Bunch and Mr Lorry Conlan are greatly appreciated.

\section{REFERENCES}

Amann, R. I., Krumholz, L. \& Stahl, D. A. (1990). Fluorescentoligonucleotide probing of whole cells for determinative, phylogenetic, and environmental studies in microbiology. $J$ Bacteriol $172,762-770$.

Amann, R. I., Lin, C., Key, R., Montgomery, L. \& Stahl, D. A. (1992). Diversity among Fibrobacter isolates: towards a phylogenetic classification. Syst Appl Microbiol 15, 23-31.

Amann, R. I., Ludwig, W. \& Schleifer, K.-H. (1995). Phylogenetic identification and in situ detection of individual microbial cells without cultivation. Microbiol Rev 59, 143-169.

Ash, C. A., Farrow, J. A. E., Dorsch, M., Stackebrandt, E. \& Collins, M. D. (1993). Comparative analysis of Bacillus anthracis, Bacillus cereus, and related species on the basis of reverse transcriptase sequencing of $16 \mathrm{~S}$ rRNA. Int J Syst Bacteriol 41, 343-346.

Bryant, M. P. (1972). Commentary on the Hungate technique for culture of anaerobic bacteria. Am J Clin Nutr 25, 1324-1328.

Bryant, M. P. (1986). Genus Ruminococcus Sijpesteijn 1948, $152^{\mathrm{AL}}$. In Bergey's Manual of Systematic Bacteriology, pp. 1093-1097. Edited by P. H. A. Sneath $\&$ others. Sydney: Williams \& Wilkins.

Chen, G. \& Russell, J. B. (1989). More monensin-sensitive, ammonia producing bacteria from the rumen. Appl Environ Microbiol 55, 1052-1057.

Collins, M. D., Lawson, P. A., Willems, A., Cordoba, J. J., Fernandez-Garayzabal, J., Garcia, P., Cai, J., Hippe, H. \& Farrow, J. A. E. (1994). The phylogeny of the genus Clostridium: proposal of five new genera and eleven new species combinations. Int J Syst Bacteriol 44, 812-826.

Dehority, B. A. \& Orpin, C. G. (1988). Development of, and natural fluctuations in, rumen microbial populations. pp. 151-183. Edited by P. N. Hobson. New York: Elsevier.

Dehority, B. A., Tirabasso, P. A. \& Grifo, J. A. P. (1989). Mostprobable-number procedures for enumerating ruminal bacteria, including the simultaneous estimation of total and cellulolytic numbers in one medium. Appl Environ Microbiol 55, 2789-2792.

Ezaki, T., Li, N., Hashimoto, Y., Miura, H. \& Yamamoto, H. (1994). $16 \mathrm{~S}$ ribosomal DNA sequences of anaerobic cocci and proposal of
Ruminococcus hanserii comb. nov. and Ruminococcus productus comb. nov. Int J Syst Bacteriol 44, 130-136.

Farris, J. S. (1977). Phylogenetic analysis under Dollo's Law. Syst Zoology 26, 77-88.

Felsenstein, J. (1993). PHYLIP (Phylogeny Inference Package). Seattle: Department of Genetics, University of Washington.

Forster, R. J., Teather, R. M., Gong, J. \& Deng, S. J. (1996). $16 \mathrm{~S}$ rDNA analysis of Butyrivibrio fibrisolvens: phylogenetic position and relation to butyrate-producing anaerobic bacteria from the rumen of white-tailed deer. Lett Appl Microbiol 23, 218-222.

Forster, R. J., Gong, J. \& Teather, R. M. (1997). Group-specific $16 \mathrm{~S}$ rRNA hybridization probes for determinative and community structure studies of Butyrivibrio fibrisolvens in the rumen. Appl Environ Microbiol 63, 1256-1260.

Fry, N. K., Fredreckson, J. K., Fishbain, S., Wagner, M. \& Stahi, D. A. (1997). Population structure of microbial communities associated with two deep, anaerobic, alkaline aquifers. Appl Environ Microbiol 63, 1498-1504.

Head, I. M., Saunders, J. R. \& Pickup, R. W. (1998). Microbial evolution, diversity, and ecology: a decade of ribosomal RNA analysis of uncultivated microorganisms. Microbial Ecol 35, $1-21$.

Hespell, R. B., Akin, D. E. \& Dehority, B. A. (1997). Bacteria, fungi, and protozoa of the rumen. In Gastrointestinal Microbiology, vol. 2, pp. 59-141. Edited by R. I. Mackie, B. A. White \& R. E. Isaacson. New York: Chapman and Hall.

Holdeman, L. V. \& Moore, W. E. C. (1974). New genus, Coprococcus, twelve new species, and emended descriptions of four previously described species of bacteria from human feces. Int $J$ Syst Bacteriol 24, 260-277.

Hungate, R. E. (1950). The anaerobic mesophilic cellulolytic bacteria. Bacteriol Rev 14, 1-49.

Hungate, R. E. (1957). The microorganisms in the rumen of cattle fed a constant ration. Can J Microbiol 3, 289-311.

Hungate, R. E. (1966). The rumen and its microbes, pp. 1-533. Edited by R. E. Hungate. New York: Academic Press.

Hungate, R. E. (1969). A roll tube method for cultivation of strict anaerobes. In Methods in Microbiology, pp. 117-132. Edited by J. R. Norris \& D. W. Ribbons. New York: Academic Press.

Jukes, T. H. \& Cantor, C. R. (1969). Evolution of protein molecules. In Mammalian Protein Metabolism, pp. 21-132. Edited by H. N. Munro. New York: Academic Press.

Krause, D. O. \& Russell, J. B. (1996). An rRNA approach for assessing the role of obligate amino acid-fermenting bacteria in ruminal amino acid deamination. Appl Environ Microbiol 62, 815- 821.

Krause, D. O., Bunch, R. J., Smith, J. M. \& McSweeney, C. S. (1999). Diversity of Ruminococcus strains: a survey of genetic polymorphisms and plant digesting ability. J Appl Bacteriol 86, 487-495.

Leedle, J. A. Z., Bryant, M. P. \& Hespell, R. B. (1982). Diurnal variations in bacterial numbers and fluid parameters in ruminal contents of animals fed low- or high-forage diets. Appl Environ Microbiol 44, 402-412.

Lin, C. \& Stahl, D. A. (1995). Taxon-specific probes for the cellulolytic Fibrobacter reveal abundant and novel equineassociated populations. Appl Environ Microbiol 61, 1348-1351.

Lin, C., Flesher, B., Capman, W. C., Amann, R. I. \& Stahl, D. A. (1994). Taxon specific hybridization probes for fiber-digesting bacteria suggest novel gut-associated Fibrobacter. Syst Appl Microbiol 17, 418-424. 
Lin, C., Raskin, L. \& Stahl, D. A. (1996). Microbiol community structure in gastrointestinal tracts of domestic animals: comparative analysis using rRNA-targeted oligonucleotide probes. FEMS Microbiol Ecol 22, 281-294.

Link, W. A. \& Sauer, J. R. (1998). Estimating population change from count data: application to the North American breeding bird survey. Ecol Appl 8, 258-268.

Mackie, R. I. (1997). Gut environment and evolution of mutualistic fermentative digestion. In Gastrointestinal Microbiology, vol. 1, pp. 13-35. Edited by R. I. Mackie \& B. A. White. New York: Chapman \& Hall.

Mackie, R. I. \& Wilkens, C. A. (1988). Enumeration of anaerobic bacterial microflora of the equine gastrointestinal tract. Appl Environ Microbiol 54, 2155-2160.

McSweeney, C. S. (1989). Cannulation of the rumen in cattle and buffaloes. Aust Vet J 66, 266-268.

Maidak, B. L., Olsen, G. J., Larsen, N., Overbeek, R., McCaughey, M. J. \& Woese, C. R. (1997). The RDP (Ribosomal Database Project). Nucleic Acids Res 25, 109-111.

Montgomery, L. \& Macy, J. M. (1982). Characterization of rat cecum cellulolytic bacteria. Appl Environ Microbiol 44, 14351443.

Montgomery, L., Flecher, B. \& Stahl, D. (1988). Transfer of Bacteroides succinogenes (Hungate) to Fibrobacter gen. nov. as Fibrobacter succinogenes comb. nov. and description of Fibrobacter intestinalis sp. nov. Int J Syst Bacteriol 38, 430-435.

Nei, M. \& Li., W.-H. (1979). Mathematical model for studying genetic variation in terms of restriction endonucleases. Proc Natl Acad Sci 76, 5269-5273.

Odenyo, A. A., Mackie, R. I., Stahl, D. A. \& White, B. A. (1994a). The use of $16 \mathrm{~S}$ rRNA-targeted oligonucleotide probes to study competition between ruminal fibrolytic bacteria : development of probes for Ruminococcus species and evidence for bacteriocin production. Appl Environ Microbiol 60, 3688-3696.

Odenyo, A. A., Mackie, R. I., Stahl, D. A. \& White, B. A. (1994b). The use of $16 \mathrm{~S}$ rRNA-targeted oligonucleotide probes to study competition between ruminal fibrolytic bacteria: pure-culture studies with cellulose and alkaline peroxide-treated wheat straw. Appl Environ Microbiol 60, 3697-3703.

Pace, N. R. (1997). A molecular view of microbial diversity and the biosphere. Science 276, 734-740.

Rainey, F. A. \& Janssen, P. H. (1995). Phylogenetic analysis by $16 \mathrm{~S}$ ribosomal DNA sequence comparison reveals two unrelated groups of species within the genus Ruminococcus. FEMS Microbiol Lett 129, 69-74.

Raskin, L., Capman, W. C., Sharp, R., Poulsen, L. K. \& Stahl, D. A. (1997). Molecular ecology of gastrointestinal ecosystems. In Gastrointestinal Microbiology, vol. 2, pp. 243-298. Edited by R. I. Mackie, R. E. White \& R. E. Isaacson. Melbourne: Chapman \& Hall.

Russell, J. B. (1985). Fermentation of cellodextrins by cellulolytic and non-cellulolytic rumen bacteria. Appl Environ Microbiol 49, $572-576$.
Sijpelsteijn, A. K. (1951). On Ruminococcus flavefaciens, a cellulose decomposing bacterium from the rumen of sheep and cattle. J Gen Microbiol 5, 869-879.

Snedecor, G. W. \& Cochran, W. G. (1980). Statistical methods, 7th edn. Ames: The Iowa State University Press.

Stackebrandt, E. \& Goebel, B. M. (1994). Taxonomic note: a place for DNA-DNA reassociation and $16 \mathrm{~S}$ rRNA sequence analysis in the present species definition in bacteriology. Int J Syst Bacteriol 44, 846-849.

Stahl, D. A., Flesher, B., Mansfield, H. R. \& Montgomery, L. (1988). Use of phylogenetically based hybridization probes for studies of ruminal microbial ecology. Appl Environ Microbiol 54, 1079-1084.

Stewart, C. S. \& Flint, H. J. (1989). Bacteroides (Fibrobacter) succinogenes, a cellulolytic anaerobic bacterium from the gastrointestinal tract. Appl Microbiol Biotechnol 30, 433-439.

Suzuki, M. T. \& Giovannoni, S. J. (1996). Bias caused by template annealing in the amplification of mixtures of $16 \mathrm{~S} \mathrm{rRNA}$ genes by PCR. Appl Environ Microbiol 62, 625-630.

Thompson, J. D., Higgins, D. G. \& Gibson, T. J. (1994). CLuSTAL W : improving the sensitivity of progressive multiple sequence alignment through sequence weighting, position-specific gap penalties and weight matrix choices. Nucleic Acids Res 22, 4673-4680.

Van de Peer, Y. \& De Wachter, R. (1994). TREECON for Windows: a software package for the construction and drawing of evolutionary trees for the Microsoft Windows environment. Comput Appl Biosci 10, 569-570.

Van De Peer, Y., Neefs, J.-M., De Rijk, P., De Vos, P. \& De Wachter, R. (1994). About the order of divergence of the major bacterial taxa during evolution. Syst Appl Microbiol 17, 32-38.

Wagner, M., Erhart, R., Manz, W., Amann, R., Lemmer, H., Wedi, D. \& Schleifer, K.-H. (1994). Development of an rRNA-targeted oligonucleotide probe specific for the genus Acinetobacter and its application for in situ monitoring in activated sludge. Appl Environ Microbiol 60, 792-800.

Weimer, P. J. (1996). Why don't ruminal bacteria digest cellulose faster? J Dairy Sci 79, 1496-1502.

Willems, A. \& Collins, M. D. (1995). Phylogenetic analysis of Ruminococcus flavefaciens, the type species of the genus Ruminococcus, does not support the reclassification of Streptococcus hansenii and Peptostreptococcus productus as ruminococci. Int $J$ Syst Bacteriol 45, 572-575.

Yang, C.-M. J. \& Russell, J. B. (1993). The effect of monensin supplementation on ruminal ammonia accumulation in vivo and numbers of amino acid fermenting bacteria. J Anim Sci 71, 3470-3476.

Zheng, D., Alm, E. W., Stahl, D. A. \& Raskin, L. (1996). Characterization of universal small-subunit rRNA hybridization probes for quantitative molecular microbial ecology studies. Appl Environ Microbiol 62, 4504-4513.

Received 21 December 1998; revised 6 April 1999; accepted 8 April 1999. 